\title{
Firm heterogeneity, absorptive capacity and technical linkages with external parties in Italy ${ }^{1}$
}

\section{Claudio Cozza, Antonello Zanfei}

\begin{abstract}
While it is widely acknowledged that internal R\&D is a fundamental source of the ability to absorb, select and use external knowledge, severe data limitations prevent from capturing differences across firms in this respect. Using a novel dataset supplied by the Italian Bureau of Statistics (ISTAT), we highlight that, when controlling for internal $R \& D$ efforts, not all firms are equally prone to gain access to external technology, and to the knowledge provided by universities in particular. We find that firms which do not only perform R\&D activities but also belong to a group exhibit a higher propensity to access to external knowledge by either contracting out $R \& D$ or cooperating with external parties, as compared to independent firms that are not organized into groups. This premium persists when controlling for different measures of internal $R \& D$ efforts. Furthermore, the differential in the propensity to access external knowledge is particularly high in the case of $R \& D$ performers belonging to foreign groups, i.e. Italian affiliates of foreign owned companies; and it is even higher in the case of the few Italian firms that have $R \& D$ activities abroad. The relative dis-advantage of independent firms, which represent the bulk of the Italian industry and include most small and medium sized enterprises, appears to be less of an obstacle in the case of linkages with universities, especially when R\&D contracting out is considered.
\end{abstract}

Jel classification: F10, F23, O33

\footnotetext{
${ }^{1}$ Acknowledgments

The authors gratefully acknowledge the remarkable work carried out at ISTAT by Giulio Perani for the construction and analysis of the RS1 dataset, which is used in this paper, and for his useful suggestions. They also thank Carmen Aina, Bernardo Balboni and Davide Castellani for useful comments and insights on the empirical analysis carried out in this paper. The usual disclaimers apply.
} 


\section{Introduction}

It is widely acknowledged that internal $R \& D$ is a fundamental source of the ability to absorb, select and use external knowledge. This idea plays a central role in analyses of innovation generation and diffusion and has been subsumed in industrial organization approaches in general $^{2}$. Empirical research has generally recognized that firms significantly differ in their access to external knowledge due to their level of "absorptive capacity", which in turn is most often identified in terms of some measure of internal R\&D efforts (Veugelers 1997, Piga and Vivarelli 2004, Cassiman and Veugelers 2006, Belderbos et al 2004, 2014, Spithoven and Teirlinck 2014). Nevertheless, due to severe data limitations, scholars are frequently unable to either satisfactorily measure such R\&D efforts, or capture other characteristics of firms that may influence their ability and propensity to gain access to complementary knowledge sources.

Using a novel dataset supplied by the Italian Bureau of Statistics (ISTAT), we are able to distinguish different measures of $R \& D$ efforts that provide a better understanding of "internal" absorptive capacity in the case of firms active in Italy. Moreover, we are enabled to identify different categories of firms that exhibit distinct propensities to access external knowledge, even controlling for these (improved) measures of internal R\&D efforts and other standard controls, such as size, industry and time dummies. The categories we identify can be associated to other abilities to absorb and utilize external knowledge that are harder to measure. In particular we focus on group belonging as a further indicator of the capacity to absorb, utilize and extract economic value from external knowledge. We find that firms which do not only perform R\&D activities but also belong to a group exhibit a higher propensity to access to external knowledge by either contracting out R\&D or cooperating with external parties, as compared to independent firms that are not organized into groups. This premium persists when controlling for different measures of internal R\&D efforts. Furthermore, the differential in the propensity to access external knowledge is particularly high in the case of R\&D

2 Economics of innovation has long emphasized the links between internal and external knowledge that reflect the systemic nature of technical change (Mowery and Rosenberg 1989, Cohen and Levinthal 1989, 1990). IO models have traditionally emphasized a dual role of spillovers: outgoing spillovers may reduce the incentives of firms to enter cooperative agreements while incoming spillovers increase the attractiveness of cooperation (De Bondt and Veugelers, 1991; Kesteloot and Veugelers, 1995; Eaton and Eswaran, 1997). More recent IO models take into account that firms can attempt to manage spillovers, trying to minimize outgoing spillovers while at the same time maximizing incoming spillovers (Cassiman et al., 2002; Martin, 2002; Amir et al., 2003). Firms can increase the effectiveness of incoming spillovers by investing in "absorptive capacity". performers belonging to foreign groups, i.e. Italian affiliates of foreign owned companies; and it is even higher in the case of the few Italian firms that have $\mathrm{R} \& \mathrm{D}$ activities abroad. The latter is a very narrow but important subset of Italian firms belonging to a group, which have significantly increased their R\&D efforts over the past decade.

The premia observed in the case of firms belonging to groups have to do with the technological and organizational advantages that are generally associated to this form of corporate governance. The correlation between group belonging, technical efficiency and innovative behavior has been analyzed for several countries $^{3}$. As documented in a number of studies, the development of business groups has traditionally characterised the top layer of Italian capitalism (Barca and Trento, 1997; Colajanni, 1991), but also involves a wide variety of firm categories, including medium sized enterprises. In fact, the so-called "Italian Mittelstand" can compensate for the lack of economies of scales and scope by joining both horizontal and vertical groups, and exploit the flexibility of this governance structure to adapt to changing market and technological conditions (Colli and Vasta, 2010), enhance R\&D investments (Cozza and Zanfei 2014) and foster technical efficiency (Zeli 2002). This should inter alia increase the ability of firms belonging to groups to access and utilize external knowledge.

Firms taking part in international groups may have even greater technological and organizational advantages than those belonging to national groups (Cantwell 1989, Doms and Jensen 1998, Zanfei 2000, Ietto-Gillies 2001, Narula and Zanfei 2005, Guadalupe et al 2012). On the one hand, multinational groups rely on extensive intra-group networks of affiliates that span across different markets and different national innovation systems. This allows units of a multinational group to benefit from the valuable knowledge that is either generated within the internal network of affiliates, though their own $R \& D$ facilities and plant level engineering, or accessed via the external network of technical alliances that each affiliate is able to set up with third parties (Zanfei 2000, Castellani and Zanfei 2006). Knowledge accumulated via internal and external networks of a multinational group is generally available to the parent company and eventually to each subsidiary at a lower cost than through arms-length transactions (Griffith et al 2006, Rabbiosi and Santagelo 2013), and can usefully complement the absorptive capacity available at the level of each individual firm. We can identify this as "intra-group absorptive capacity", which can be expected to be substantially higher in the case of multinational groups than in the case of national groups, let alone the case of

\footnotetext{
3 This is particularly the case of studies on the correlation between group belonging and economic performance in newly industrializing countries. See Hobday (1995) for East Asian countries, and Mahmood and Mitchell (2004) for Korea and Taiwan in particular.
} 
independent firms. Such additional absorptive capacity should thus further increase the ability of firms belonging to multinational groups - i.e. foreign owned companies and national firms with (R\&D) activities abroad - to evaluate and access external knowledge.

On the other hand, firms belonging to multinational groups have additional advantages that derive from the possibility of applying - and extracting economic value from the application of - the available knowledge to an extensive number and variety of national and local contexts, where the multinational is located and active (Dunning 1981, Caves 1996). This advantage applies to all knowledge available, whichever may be the channel though which it is generated or assimilated, hence including the knowledge accessed from external sources. Thus, the ubiquitous nature of multinationals makes it significantly more advantageous for its units to search for, and gain access to, external sources of knowledge.

Therefore, multinational companies combine what we have called "intra-group absorptive capacity", which increases the ability to gain access to external knowledge, with the advantages of extracting greater rents from its application. This combination of characteristics helps explain the extra propensity of firms belonging to multinational groups to set up technical linkages with third parties.

From this perspective, we shall explore the links between group belonging, absorptive capacity and access to external knowledge using an extremely detailed database on R\&D activities of 13,675 firms active in Italy over 2000-2010. The remainder of this paper is organized as follows. Section 2 provides a description of data used in this paper and illustrates the patterns of internal and external R\&D activities of firms active in Italy. In section 3 we produce estimates of the propensity of different categories of Italian firms to resort to external knowledge sourcing. Section 4 concludes.

\section{Data description}

This paper exploits a novel dataset based on the Italian R\&D survey (RS1) conducted by ISTAT (the Italian Bureau of Statistics) and targeted at all potential R\&D performers. The survey follows a census approach and is structured according to the OECD Frascati Manual (2002) guidelines. Respondents to the RS1 questionnaire provide ISTAT with detailed data on internal R\&D efforts. The ones used in this paper refer to the amount of intra-muros R\&D expenditures, their persistence over time and the number of $R \& D$ employees. We will also use data deriving from respondents' answers to specific questions on external linkages of these R\&D performers: extra-muros R\&D expenditures and technical cooperation, which are both broken down by type of partners (including other firms, private and public research institutions, and Universities). Finally, the RS1 database provides complementary information on firm size (in terms of total employees), capital expenditure, main (NACE five digit) sector of activity, and indicates whether the responding firm belongs to a national or foreign group.

Based on the ISTAT RS1 survey over the 2001-2010 we built an unbalanced panel of R\&D performers active in Italy, with 39,152 observations, corresponding to a total of 13,675 firms performing $R \& D$ at least in one year.

Breaking this sample down by typology of firm, in figure 1 we can notice that a large majority (more than $60 \%$ of total respondents) is represented by $R \& D$ performers that do not belong to a group (Italian firms Not in a Group, ING). About one third of the sample is composed by Italian firms belonging to Groups (IGP), while a minor and decreasing share is represented by subsidiaries of Foreign Owned Groups (FOR), that has been shrinking from about $10 \%$ in 2001 to slightly more than $5 \%$ of all the firms recorded in the dataset at the end of the period.

As shown in table 1, FOR are about $20 \%$ larger (in terms of employees) than IGP, and approximately 7 times as large as ING. A similar ranking can be observed when R\&D expenditure per firm is considered, with FOR spending 40\% more than IGP and 9 times as much as ING.

The hierarchy persists if unit R\&D efforts are calculated in terms of $R \& D$ expenditure per $R \& D$ employees. One should note, however, that data on R\&D employees are subject to important limitations especially in the case of SMEs, which are a dominant component of ING. In fact it is quite common that workers are multi-task in small sized firms, and R\&D activities might well be only one of the multiple roles played by them according to needs and circumstances. Hence using head counts might lead to substantial errors in the measurement of the actual availability of R\&D workforce ${ }^{4}$. A better, albeit not fully satisfactory, solution of this problem, would be making use of full time equivalent (FTE) employment data, which allow to more accurately account for the use of part-time $R \& D$ contracts, and for spare time $R \& D$ efforts produced by workers that are mainly involved in other activities. We shall deal with these data constraints when using multivariate techniques to test the links between internal R\&D effort and external knowledge sourcing. Suffice here to note that differences across firm typologies are much lower when R\&D personnel is measured in terms of FTE rather than head counts, as shown in Table 1.

\footnotetext{
${ }^{4}$ Whether this should lead to overestimate, rather than underestimate, the actual R\&D efforts, is an empirical question. On the one hand, firms might be induced to register multi-task workers according to their prevailing activities, a practice that is most likely to produce a downward bias in the measurement of working time devoted to R\&D. On the other hand, head-counts would lead to an overestimation of R\&D efforts in the case of firms making an extensive use of part-time contracts.
} 


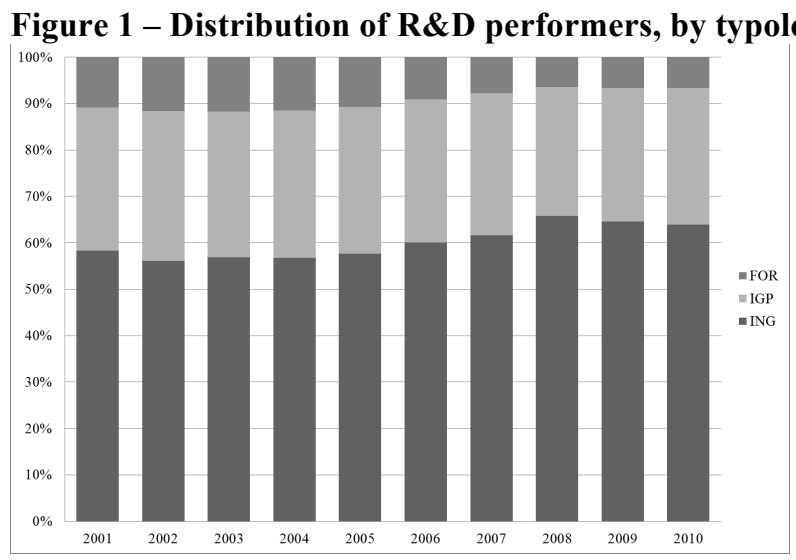

Source: elaborations on ISTAT RS1

Table 1 - Description of main RS1 variables, by typology of firm

\begin{tabular}{|c|c|c|c|c|}
\hline & & ING & IGP & FOR \\
\hline \multirow{2}{*}{ Number of total R\&D performers } & Year 2010 & 3,775 & 1,742 & 393 \\
\hline & Growth rate & $250.6 \%$ & $218.5 \%$ & $140.8 \%$ \\
\hline \multirow{2}{*}{$\begin{array}{l}\text { Average size of firms (number of employees } \\
\text { FTE) }\end{array}$} & Year 2010 & 88.33 & 499.33 & 619.08 \\
\hline & Growth rate & $-1.6 \%$ & $-4.2 \%$ & $-3.6 \%$ \\
\hline \multirow{2}{*}{$\begin{array}{l}\text { Average Intra-muros R\&D expenditure per } \\
\text { firm (thousand of euros) }\end{array}$} & Year 2010 & 574.97 & $3,672.44$ & $5,117.95$ \\
\hline & Growth rate & $1.3 \%$ & $-2.1 \%$ & $-5.4 \%$ \\
\hline \multirow{2}{*}{ R\&D / R\&D employees } & Year 2010 & 41.79 & 77.87 & 104.42 \\
\hline & Growth rate & $-1.4 \%$ & $-1.4 \%$ & $-0.6 \%$ \\
\hline \multirow{2}{*}{ R\&D / R\&D employees FTE } & Year 2010 & 125.70 & 144.57 & 155.28 \\
\hline & Growth rate & $7.1 \%$ & $3.9 \%$ & $2.9 \%$ \\
\hline \multirow{2}{*}{$\begin{array}{l}\text { Average Extra-muros R\&D expenditure per } \\
\text { firm (thousand of euros) }\end{array}$} & Year 2010 & 125.56 & 752.93 & 518.45 \\
\hline & Growth rate & $22.8 \%$ & $10.0 \%$ & $-12.2 \%$ \\
\hline \multirow{2}{*}{ Share of firms cooperating, on total firms } & Year 2010 & $29.7 \%$ & $39.8 \%$ & $42.2 \%$ \\
\hline & Growth rate & $9.7 \%$ & $6.8 \%$ & $1,4 \%$ \\
\hline \multirow{2}{*}{$\begin{array}{c}\text { Share of firms cooperating with university, on } \\
\text { total firms }\end{array}$} & Year 2010 & $12.9 \%$ & $19.1 \%$ & $16.0 \%$ \\
\hline & Growth rate & $11.2 \%$ & $6.1 \%$ & $-1.5 \%$ \\
\hline
\end{tabular}

Source: elaborations on ISTAT RS1

Note: the growth rate is calculated as 2001-2010 CAGR

Looking at growth rates, one can observe that, while the number of all types of R\&D performers has been significantly augmenting over 2001-2010, this increase has been much higher in the case of IGP, and even more so in the case of ING, than in the case of FOR. Moreover, firms of all categories have on average reduced their size over the same period, and the decrease has been higher in the case of FOR and IGP than in the case of ING (which were relatively small already at the beginning of the period). Firms belonging to FOR and IGP categories have also experienced decreases in R\&D per firm, while ING have instead improved their performance in terms of this indicator. The scenario changes a bit when $R \& D$ efforts are measured in terms of FTE R\&D personnel: all firm categories have increased their R\&D per FTE employees, but the growth rate of ING firms is one and a half times the rate observed for IGT companies, and more than twice the rate of FOR firms.

To summarize, group belonging is associated with higher R\&D intensity. Both $R \& D$ per firm and $R \& D$ per researcher are highest for subsidiaries of Foreign Groups (FOR), somewhat lower but still high in the case of firms belonging to Italian groups (IGP), and it is lowest in the case of firms not belonging to a group (ING). However, things are changing, as the latter firm category experiences the highest growth rates, while 
FOR are decreasing their R\&D efforts in Italy, and IGP place themselves roughly in between.

The three typologies of firms exhibit different patterns also when looking at the strategies they use to access external knowledge. We look at two alternative channels: Extra-muros R\&D, indicating the amount of $\mathrm{R} \& \mathrm{D}$ expenditure that is contracted out to third parties; and technical collaborations with other firms and institutions.

As shown in Table 1, group belonging is also associated to remarkably higher values of $R \& D$ extramuros per firm, relative to the case of ING. However, firms belonging to Italian groups appear to be more involved in this external sourcing strategy than subsidiaries of foreign groups. Moreover, ING appear to have significantly increased their extra muros R\&D over time, and play a non trivial role in contracting out R\&D to universities. Figure 2 confirms that firms belonging to groups play a greater role in extra-muros $R \& D$, but have significantly reduced their efforts to use this channel to access external knowledge over time, particularly in the case of subsidiaries of foreign multinationals, while ING have experienced a remarkable increase in this respect.

Figure 2 - Average Extra-muros R\&D expenditure per firm (in thousands of Euro), by typology of firm, selected years

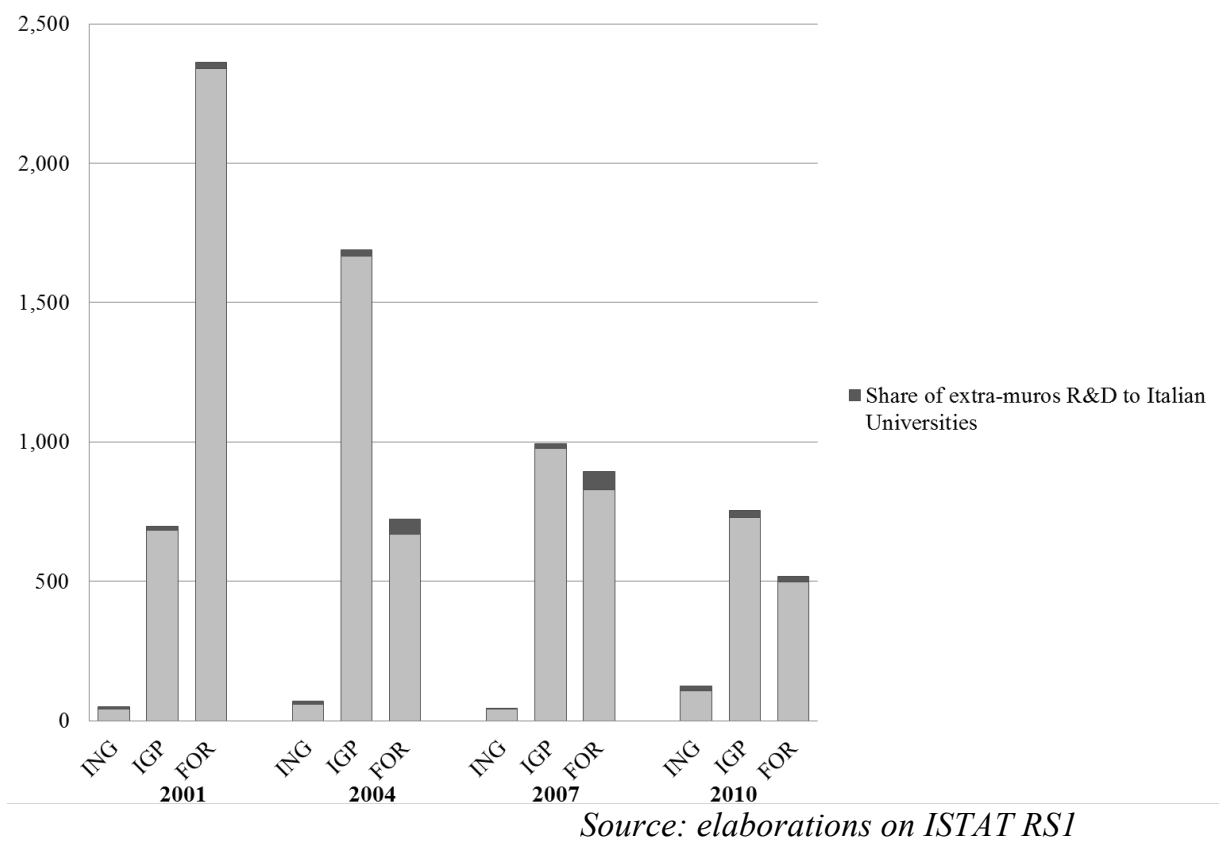

The other strategy we consider as a measure of external knowledge sourcing, i.e. technical collaborations, can only be measured in terms of a dummy that identifies whether or not the observed firm got involved in R\&D collaborations in any given year over the examined period. Figure 3 illustrates the share of firms cooperating in general and the share of firms cooperating with universities in Italy. We find that FOR firms are the most involved in cooperation, followed by IGP and then by ING. However, the overall number of ING firms cooperating in general and with Italian universities in particular is increasing (the CAGR is $9.7 \%$ and $11.2 \%$ respectively), while this increase is lower for IGP firms $(6.8 \%$ and $6.1 \%)$ and even negative for the FOR category when cooperation with Italian universities is considered (the CAGR is $1.4 \%$ and $1.5 \%$ respectively). This translates into a decrease of the share of collaborations in which FOR and IGP firms are involved, whereas the share remains quite stable for ING.

The degree of cooperation with Foreign universities is always very low: the share of firms involved in such collaborations ranges between $1 \%$ and $8 \%$ of total firms. Also in this case, the ING typology is the only one showing an increase over the examined period.

To conclude this overview of descriptive evidence, some heterogeneity exists across the examined categories of Italian firms, both in terms of internal R\&D efforts and in terms of external knowledge sourcing strategies. On the one hand, the subsets of firms that exhibit the highest R\&D intensity - IGP and FOR - are also the ones showing the highest intensity of outsourcing strategies (as shown in table 1). On the other hand, hierarchies we have observed in the case of R\&D intensity do not seem to perfectly mirror into hierarchies in terms of external knowledge sourcing. FOR do not always outperform all other firms, IGP often take the lead especially in extra-muros R\&D, ING firms have significantly increased their overall R\&D efforts throughout the whole period, and have intensified their extra-muros $R \& D$ contracting out and technical cooperation in general and with universities in particular. 
Figure 3 - Shares of firms involved in $R \& D$ collaborations, by category of $R \& D$ spenders

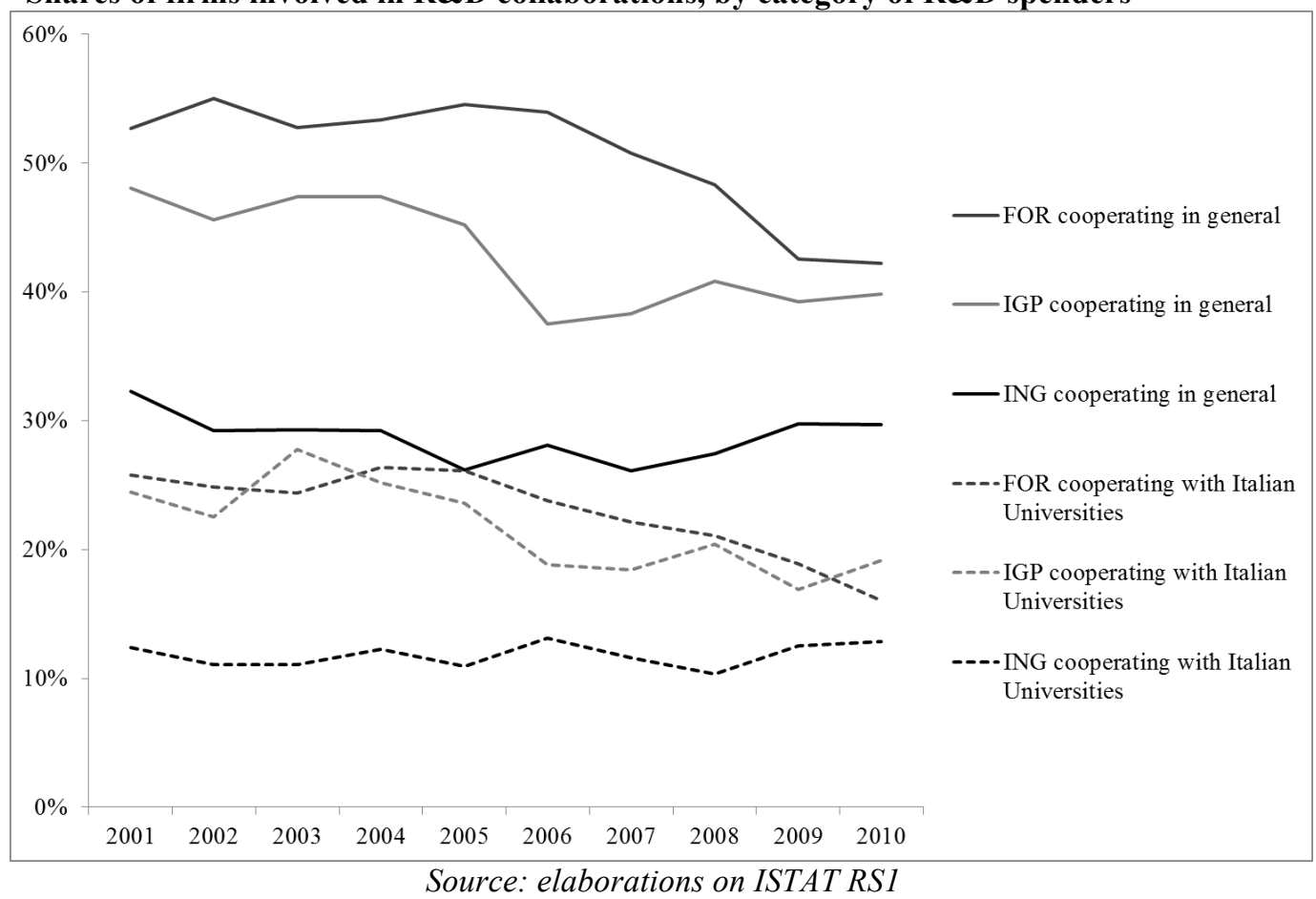

It thus appears that the links between internal and external R\&D are somewhat mediated by the characteristics of firms under observation, and by the nature of third parties involved in external R\&D sourcing strategies, with universities playing a peculiar role in this respect. Of course, examining the propensity of different categories of firms to resort to external knowledge sources requires that several sources of heterogeneity are simultaneously controlled for. This is what we shall do in the next section.

3. The links between group belonging, absorptive capacity and external knowledge sourcing

We have run regressions to test differences in the propensity of firms to access external knowledge in the Italian industry, conditional on a number of controls. See tables $2 \mathrm{a}$ and $2 \mathrm{~b}$ for variable definition and descriptive statistics.

The first set of tests has been conducted using the yearly value of Extra-muros R\&D expenditure in 20012010 as a dependent variable. This captures the amount of research activity contracted out by firms to external parties, including public and private research institutions and other companies. We employ OLS with heteroscedasticity-consistent standard errors to produce estimates with firms not belonging to a group which we identified as ING in section 2 - as baseline category. In column (1) of table 3 we show how firms belonging to Italian groups (IGP) and affiliates of foreign owned (multinational) groups (FOR) differ from independent companies in terms of $R \& D$ contracting out activities, controlling only for usual measures of size, firm level capital expenditure, sector and time dummies. As expected, FOR and IGP firms exhibit a much higher propensity to resort to extra- muros $\mathrm{R} \& \mathrm{D}$ relative to companies not belonging to groups, with a substantial premium of $30.4 \%$ and $23.4 \%$ respectively. As highlighted in column (2) intramuros R\&D, as a proxy of "internal absorptive capacity", explains an important part of these premia. In fact the difference in the propensity to contracting out R\&D shrinks by over one third in the case of FOR and slightly less than $30 \%$ in the case of IGP. There remains a remarkable differential between FOR and IGP relative to the baseline category. The hierarchy between FOR (19.7\% higher propensity) and IGP (17.6\% higher propensity) also persists, although it has diminished to a tiny $2 \%$. Roughly the same premia relative to independent firms and the same hierarchy are confirmed when further controls for R\&D efforts are introduced in column (3), to better capture "internal absorptive capacity". Given that controls for firms size (measured in terms of total FTE employees) are present for all equations, coefficients estimated for intra-muros $R \& D$ and for $R \& D$ employees reflect how the propensity to $R \& D$ contracting is sensitive to two different measures of R\&D intensity, one expressed in terms of expenditures and the other expressed in terms of personnel dedicated to R\&D. Due to data limitation, extant literature has most frequently used variants of the latter measure (R\&D personnel/total employees) as an indicator of R\&D intensity. Column (3) of table 3 shows that it is $R \& D$ expenditure, more than the availability of additional R\&D employees, that explains the larger share of the propensity to contract R\&D to external parties ${ }^{5}$. The persistence of R\&D activity over time, proxied by the number of years firms have

\footnotetext{
${ }^{5}$ Running separate regressions by typology of firms, it comes out that R\&D employees have always a positive and significant impact only in the case of ING firms, while they are always not significant for foreign subsidiaries.
} 
reported a positive value of $\mathrm{R} \& \mathrm{D}$ in the annual RS1 survey on R\&D performers conducted by ISTAT in the examined period (2001-2010), also helps explain differences in R\&D contracted out, although this seems to play a relatively minor role.

\section{Table 2a - Variable definition}

Dependent variables

LN Extra-MUROS R\&D: (Natural Log of) Extra-muros R\&D expenditure

LN Extra-muros to University: (Natural Log of) Extra-muros R\&D expenditure commissioned to Italian Universities

Cooperation: dummy "cooperation with an external partner"

Cooperation with Universities: dummy "cooperation with Italian University"

\section{Measures of internal R\&D efforts}

Ln Intra-muros R\&D: (Natural Log of) Intra-muros R\&D expenditure

R\&D Persistence: number of years with positive Intra-muros $R \& D$ (persistence)

Ln R\&D Employees: (Natural Log of) number of R\&D employees FTE (full time equivalent)

Controls for firm tipologies

ING: dummy "firm not in a group"

IGP: dummy "firm in an Italian group"

FOR: dummy "subsidiary of a foreign group"

IGNFR: dummy for "firm in an Italian group without research performed abroad"

IGFR: dummy for "firm in an Italian group with research performed abroad"

Other controls

Size: (Natural Log of) number of firm employees FTE (Size control)

Sector: Hi-tech, Medium-hi-tech, Medium-low-tech, Low-tech, KIS, L(ess)KIS, Other

Capital expenditures: dummy for "R\&D expenditure for Machinery, Equipment and Software"

Time dummies

Table $2 \mathbf{b}$ - descriptive statistics

\begin{tabular}{|c|c|c|c|c|c|}
\hline \multicolumn{6}{|c|}{ Descriptive statistics } \\
\hline & $\mathrm{N}$ & Min & Max & Mean & Std. Dev \\
\hline ING & 39,152 & 0 & 1 & 0.612 & 0.487 \\
\hline IGP & 39,152 & 0 & 1 & 0.302 & 0.459 \\
\hline FOR & 39,152 & 0 & 1 & 0.086 & 0.281 \\
\hline IGNFR & 39,152 & 0 & 1 & 0.287 & 0.452 \\
\hline IGFR & 39,152 & 0 & 1 & 0.014 & 0.119 \\
\hline Employees FTE & 39,152 & 0.750 & 62,456 & 289.468 & $1,701.357$ \\
\hline Capital expenditure & 39,152 & 0 & 1 & .418 & 0.493 \\
\hline Intra-muros R\&D & 39,152 & 1 & 779,778 & $2,158.260$ & $14,756.887$ \\
\hline R\&D Persistence & 39,152 & 1 & 10 & 4.674 & 2.827 \\
\hline R\&D employees & 39,152 & 0 & 8,012 & 21.561 & 115.211 \\
\hline Extra-muros R\&D & 39,152 & 0 & 656,019 & 432.150 & $8,004.167$ \\
\hline Extra-muros to University & 39,152 & 0 & 64,241 & 16.670 & 487.642 \\
\hline Cooperation & 39,152 & 0 & 1 & 0.345 & 0.475 \\
\hline $\begin{array}{l}\text { Cooperation with } \\
\text { University }\end{array}$ & 39,152 & 0 & 1 & 0.155 & 0.362 \\
\hline
\end{tabular}


Table 3 - The propensity to contracting our extra-muros R\&D. OLS regressions with robust standard errors / dependent variable : LN Extra-muros

\begin{tabular}{|c|c|c|c|c|}
\hline & 1 & 2 & 3 & 4 \\
\hline VARIABLES & $\begin{array}{l}\text { Ln Extra-muros } \\
\text { R\&D }\end{array}$ & $\begin{array}{l}\text { Ln Extra-muros } \\
\text { R\&D }\end{array}$ & $\begin{array}{c}\text { Ln Extra-muros } \\
\text { R\&D }\end{array}$ & $\begin{array}{l}\text { Ln Extra-muros } \\
\text { R\&D }\end{array}$ \\
\hline \multirow{2}{*}{ IGP } & $0.234 * * *$ & $0.168 * * *$ & $0.176^{* * *}$ & \\
\hline & $(0.027)$ & $(0.026)$ & $(0.026)$ & \\
\hline \multirow[t]{2}{*}{ IGNFR } & & & & $0.118 * * *$ \\
\hline & & & & $(0.026)$ \\
\hline \multirow{2}{*}{ IGFR } & & & & $2.044 * * *$ \\
\hline & & & & $(0.148)$ \\
\hline \multirow[t]{2}{*}{ FOR } & $0.304 * * *$ & $0.197 * * *$ & $0.208 * * *$ & $0.261 * * *$ \\
\hline & $(0.052)$ & $(0.051)$ & $(0.051)$ & $(0.051)$ \\
\hline \multirow[t]{2}{*}{ Ln Intra-muros R\&D } & & $0.331 * * *$ & $0.228 * * *$ & $0.216^{* * *}$ \\
\hline & & $(0.012)$ & $(0.017)$ & $(0.017)$ \\
\hline \multirow[t]{2}{*}{ R\&D Persistence } & & & $0.030 * * *$ & $0.026^{* * *}$ \\
\hline & & & $(0.004)$ & $(0.004)$ \\
\hline \multirow[t]{2}{*}{ Ln R\&D Employees } & & & $0.123 * * *$ & $0.116 * * *$ \\
\hline & & & $(0.018)$ & $(0.018)$ \\
\hline \multirow[t]{2}{*}{ Constant } & $-0.470 * * *$ & $-1.326 * * *$ & $-1.010 * * *$ & $-0.851 * * *$ \\
\hline & $(0.066)$ & $(0.076)$ & $(0.088)$ & $(0.087)$ \\
\hline Number of observations & 39,152 & 39,152 & 39,152 & 39,152 \\
\hline Adjusted $\mathrm{R}^{2}$ & 0.102 & 0.129 & 0.131 & 0.141 \\
\hline
\end{tabular}

Size, sector, capital expenditure controls and time dummies included

Robust standard errors in parentheses

$* * * \mathrm{p}<0.01, * * \mathrm{p}<0.05, * \mathrm{p}<0.1$

It thus appears that introducing additional proxies of internal R\&D efforts does capture some aspects of heterogeneity, helps identify $R \& D$ expenditures as the key aspect of internal absorptive capacity (relative to other indicators of R\&D efforts), and improves the fit of estimates (as confirmed by the R-squared values in the tables).

Nevertheless, group belonging remains a fundamental structural characteristic that explains differences in the propensity to $R \& D$ contracting to external parties by a factor of $18-20 \%$. We interpret this result as consistent with our reading of group belonging as associated to additional technological and organizational assets that increase the ability of firms to explore, evaluate and access external knowledge. As argued in the introduction, firms organized into groups appear to exhibit an additional absorptive capacity, due to their possibility of drawing from different repositories of knowledge within the group itself. This is what we have identified as "intra-group" absorptive capacity that can be used to improve firms' own ability to evaluate and assimilate external technology, know how and practices. Moreover, our results can be seen as confirming the advantages of group belonging also in terms of more extensive application and exploitation of knowledge relative to independent firms, hence increasing the expected advantages from access to external sources.

What about the extra-advantage of multinationality? We have suggested in the introductory section that multinational groups should be expected to have an extra endowment of absorptive capacity and greater applications opportunities stemming from their more extensive internal networks of affiliates and external networks of collaborations, spanning across different countries, markets and innovation systems. From this perspective, one might have expected the premium associated to FOR to be higher than observed in table 3, as these are by definition firms belonging to (foreign owned) multinational groups active in Italy. These firms do exhibit a slightly greater premium than IGPs in terms of extra-muros $\mathrm{R} \& \mathrm{D}$ relative to independent firms. What should be noted, however, is that firms belonging to Italian groups (IGP) include inter alia those companies that are part of nationally controlled groups with foreign activities, i.e. Italian multinationals. Unfortunately the available data do not allow to fully separate Italian uninational from Italian multinational groups. It is rather possible to identify a subset of multinationals that is constituted by those Italian firms that have $\mathrm{R} \& \mathrm{D}$ activities abroad. These are also by definition part of multinational groups, and represent a particularly dynamic fraction of the Italian economy, a restricted minority of firms that are able to overcome the costs and risks of setting up a foreign research lab. As illustrated in more details in other works (cf. Cozza and Zanfei 2014), there are only a few dozens of such firms (124 such firms are monitored in the ISTAT-RS1 dataset, with over two thirds of outward R\&D in the hands of the top ten $R \& D$ investors). However, they account for over a quarter of total Gross National R\&D expenditure and they carry 
out more than three quarters of their foreign $R \& D$ activities in a few destination countries (Brazil, Germany, France and the US). In other words these firms represent the very top of the iceberg in the Italian innovation system and are most likely to outperform other companies active in Italy also in terms of their ability to access external knowledge. We test this hypothesis in column 4 of table 3 , where IGP are separated into two subsets, that is firms that do belong to an Italian group but do not have foreign $R \& D$ activities (IGNFR); and those that not only belong to an Italian group but also carry out foreign research activity (IGFR). As shown in column 4, the latter category of firms has a much higher propensity to $R \& D$ contracting relative to the baseline category of independent firms, a premium that is also much higher than in the case of FOR firms themselves. On the one hand this result confirms that IGFR are really the top of the iceberg as suggested, and they are particularly in the position to evaluate, access and absorb external knowledge. On the other hand, foreign companies appear to be relatively less prone to extra-muros $R \& D$, possibly revealing a weaker profile of foreign $R \& D$ investors active in Italy. This view is roughly consistent with previous evidence on the low and decreasing involvement of foreign firms in R\&D and other value added activities in Italy (Cozza and Zanfei 2014, Dachs et al 2014).

Overall, by comparing coefficients estimated in table 3 column 4 we find that the extra-advantages associated to multinationality are indeed very important, and explain a substantial part of heterogeneity in terms of extra-muros R\&D activity. In fact, firms belonging to multinational groups not only largely outperform independent firms in terms of extra-muros $R \& D$, but they also exhibit premia that are more than twice as high as the ones characterizing IGNFR in the case of foreign R\&D investors in Italy (FOR), and 17 times as high in the case of Italian firms with foreign $R \& D$ activities (IGFR).

We also examined extra-muros $R \& D$ contracted out to a specific institution, namely Italian universities ${ }^{6}$. As illustrated in the descriptive section of this paper, this is a relatively minor albeit significantly increasing fraction of total extra-muros R\&D in Italy. In table 4, where the dependent variable is Extra-muros R\&D to universities, differences across our firm categories are much lower. In the baseline model in column (1), premia range from $5.4 \%$ in the case of FOR to $2.7 \%$ in the case of IGP; while differences disappear once R\&D efforts are appropriately controlled for in columns (2) and (3). The only firm category which exhibits a more substantial premium in terms of extra-muros R\&D to universities, is the (very circumscribed) subset of Italian firms with foreign $R \& D$ activities (IGFR), as shown in column 4 of table 4 . The latter result might be interpreted as a confirming the very specific role played by the few Italian firms with R\&D activities abroad, which are inter alia likely to be able to access and

\footnotetext{
${ }^{6}$ The RS1 survey also asks whether the firm has R\&D contracted out to foreign public institutions, including universities abroad. However, figures on this option are close to zero for all years in the considered period.
}

utilize research at the scientific and technological frontier produced by universities. What is most striking, however, is that there seem to exist no significant differences between independent firms and firms belonging to groups in the case of extra-muros R\&D to universities, with the relevant but very peculiar case of IGFR. In other words, independent firms have a much the same likelihood to contract R\&D out to universities, as FOR and non internationalized firms belonging to Italian groups (IGNFR). This is in line with the descriptive evidence which we have shown, that independent firms are indeed very active in extra-muros R\&D to universities and have increased their share of extra-muros $R \& D$ contracted out to these institutions over the decade under observation. The result we obtained is also roughly consistent with previous research that has emphasized that while small and medium sized firms - which are the bulk of independent firms monitored by ISTAT-RS1 encounter greater obstacles to access external knowledge due to their limited absorptive capacity (Belderbos et al. 2004), they are also particularly interested in gaining access to technological spillovers especially when appropriability concerns are less important (Audretsch and Vivarelli 1996, Cassiman and Veugelers 2002, Chun and Mun 2010). This combination of low absorptive capacity, higher need for external knowledge, and lower capacity to appropriate results of research, might help explain why independent firms are relatively more prone to interact with, and contract research out to, universities, rather than other more market oriented institutions.

We also focused on technological cooperation with third parties, including once again public and private research institutions and other companies (rivals, customers and suppliers). In this case the dependent variable is a dummy that takes value one in case the observed firm participates in a technical linkage with third parties (zero otherwise). Logit estimates with robust standard errors referring to cooperation are shown in table 5 . Results are quite similar to the ones we obtained when we examined extra-muros R\&D, and appear even neater in terms of premia and hierarchies. Here too, FOR and IGP exhibit higher propensity to cooperate than independent firms, even when controlling for different measures of internal R\&D efforts; FOR is characterized by a higher premium than IGP in general, a difference that is more substantial than the one observed in the case of extra-muros R\&D; IGFR are starring in this case too, and appear to be the best performers also in terms of technological cooperation. As shown in column 4 of table 5, the premium observed in the case of IGFR is almost twice as high as the one characterizing FOR, and more than 3 times as high as the one characterizing IGNFR. These results are very much consistent with the view we have suggested: firms belonging to a group, and to an international group in particular, are likely to have extra advantages in terms of their ability to explore, evaluate, assimilate and utilize external knowledge. 
Table 4. - The propensity to contracting out extra-muros R\&D to universities. OLS regressions with robust standard errors / dependent variable: LN Extra-muros to University

\begin{tabular}{|c|c|c|c|c|}
\hline & 1 & 2 & 3 & 4 \\
\hline VARIABLES & $\begin{array}{l}\text { Ln Extra-muros } \\
\text { R\&D to } \\
\text { University }\end{array}$ & $\begin{array}{l}\text { Ln Extra-muros } \\
\text { R\&D to } \\
\text { University }\end{array}$ & $\begin{array}{l}\text { Ln Extra-muros } \\
\text { R\&D to } \\
\text { University }\end{array}$ & $\begin{array}{l}\text { Ln Extra-muros } \\
\text { R\&D to } \\
\text { University }\end{array}$ \\
\hline \multirow[t]{2}{*}{ IGP } & $0.027 * *$ & 0.003 & 0.006 & \\
\hline & $(0.013)$ & $(0.013)$ & $(0.013)$ & \\
\hline \multirow[t]{2}{*}{ IGNFR } & & & & -0.005 \\
\hline & & & & $(0.013)$ \\
\hline \multirow[t]{2}{*}{ IGFR } & & & & $0.388 * * *$ \\
\hline & & & & $(0.088)$ \\
\hline \multirow[t]{2}{*}{ FOR } & $0.054 * *$ & 0.016 & 0.020 & 0.031 \\
\hline & $(0.026)$ & $(0.026)$ & $(0.026)$ & $(0.026)$ \\
\hline \multirow[t]{2}{*}{ Ln Intra-muros R\&D } & & $0.117 * * *$ & $0.078 * * *$ & $0.075 * * *$ \\
\hline & & $(0.006)$ & $(0.009)$ & $(0.009)$ \\
\hline \multirow[t]{2}{*}{ R\&D Persistence } & & & $0.011 * * *$ & $0.011 * * *$ \\
\hline & & & $(0.002)$ & $(0.002)$ \\
\hline \multirow[t]{2}{*}{ Ln R\&D Employees } & & & $0.047 * * *$ & $0.045 * * *$ \\
\hline & & & $(0.009)$ & $(0.009)$ \\
\hline \multirow[t]{2}{*}{ Constant } & $-0.440 * * *$ & $-0.743 * * *$ & $-0.622 * * *$ & $-0.590 * * *$ \\
\hline & $(0.032)$ & $(0.040)$ & $(0.044)$ & $(0.044)$ \\
\hline Number of observations & 39,152 & 39,152 & 39,152 & 39,152 \\
\hline Adjusted $\mathrm{R}^{2}$ & 0.057 & 0.072 & 0.074 & 0.074 \\
\hline
\end{tabular}

Size, sector, capital expenditure controls and time dummies included

Robust standard errors in parentheses $* * * \mathrm{p}<0.01, * * \mathrm{p}<0.05, * \mathrm{p}<0.1$

Table 5 - The propensity to $R \& D$ collaboration. LOGIT regressions with robust standard errors / dependent variable : Cooperation

\begin{tabular}{|c|c|c|c|c|}
\hline & 1 & 2 & 3 & 4 \\
\hline VARIABLES & Cooperation & Cooperation & Cooperation & Cooperation \\
\hline \multirow[t]{2}{*}{ IGP } & $0.378 * * *$ & $0.329 * * *$ & $0.333 * * *$ & \\
\hline & $(0.027)$ & $(0.027)$ & $(0.028)$ & \\
\hline \multirow[t]{2}{*}{ IGNFR } & & & & $0.309 * * *$ \\
\hline & & & & $(0.028)$ \\
\hline \multirow[t]{2}{*}{ IGFR } & & & & $1.100 * * *$ \\
\hline & & & & $(0.097)$ \\
\hline \multirow[t]{2}{*}{ FOR } & $0.614 * * *$ & $0.544 * * *$ & $0.547 * * *$ & $0.565 * * *$ \\
\hline & $(0.042)$ & $(0.043)$ & $(0.043)$ & $(0.043)$ \\
\hline \multirow[t]{2}{*}{ Ln Intra-muros R\&D } & & $0.246 * * *$ & $0.200 * * *$ & $0.196 * * *$ \\
\hline & & $(0.011)$ & $(0.020)$ & $(0.020)$ \\
\hline \multirow[t]{2}{*}{ R\&D Persistence } & & & $0.034 * * *$ & $0.033 * * *$ \\
\hline & & & $(0.004)$ & $(0.004)$ \\
\hline \multirow[t]{2}{*}{ Ln R\&D Employees } & & & $0.045 * *$ & $0.043 * *$ \\
\hline & & & $(0.021)$ & $(0.021)$ \\
\hline \multirow[t]{2}{*}{ Constant } & $-2.008 * * *$ & $-2.660 * * *$ & $-2.553 * * *$ & $-2.491 * * *$ \\
\hline & $(0.064)$ & $(0.071)$ & $(0.092)$ & $(0.092)$ \\
\hline Number of observations & 39,152 & 39,152 & 39,152 & 39,152 \\
\hline Pseudo $\mathrm{R}^{2}$ & 0.068 & 0.080 & 0.081 & 0.082 \\
\hline
\end{tabular}

Size, sector, capital expenditure controls and time dummies included

Robust standard errors in parentheses $* * * \mathrm{p}<0.01, * * \mathrm{p}<0.05,{ }^{*} \mathrm{p}<0.1$ 
Table 6 - The propensity to $R \& D$ cooperation with universities. LOGIT regressions with robust standard errors / dependent variable: Cooperation with University

\begin{tabular}{|c|c|c|c|c|}
\hline & 1 & 2 & 3 & 4 \\
\hline VARIABLES & $\begin{array}{l}\text { Cooperation } \\
\text { with University }\end{array}$ & $\begin{array}{l}\text { Cooperation } \\
\text { with University }\end{array}$ & $\begin{array}{l}\text { Cooperation } \\
\text { with University }\end{array}$ & $\begin{array}{r}\text { Cooperation } \\
\text { with University }\end{array}$ \\
\hline \multirow[t]{2}{*}{ IGP } & $0.315 * * *$ & $0.242 * * *$ & $0.254 * * *$ & \\
\hline & $(0.035)$ & $(0.035)$ & $(0.036)$ & \\
\hline \multirow[t]{2}{*}{ IGNFR } & & & & $0.238 * * *$ \\
\hline & & & & $(0.036)$ \\
\hline \multirow[t]{2}{*}{ IGFR } & & & & $0.615 * * *$ \\
\hline & & & & $(0.102)$ \\
\hline \multirow[t]{2}{*}{ FOR } & $0.259 * * *$ & $0.126^{* *}$ & $0.145 * * *$ & $0.160 * * *$ \\
\hline & $(0.052)$ & $(0.054)$ & $(0.054)$ & $(0.054)$ \\
\hline \multirow[t]{2}{*}{ Ln Intra-muros R\&D } & & $0.347 * * *$ & $0.200 * * *$ & $0.197 * * *$ \\
\hline & & $(0.015)$ & $(0.027)$ & $(0.027)$ \\
\hline \multirow[t]{2}{*}{ R\&D Persistence } & & & $0.060 * * *$ & $0.059 * * *$ \\
\hline & & & $(0.006)$ & $(0.006)$ \\
\hline \multirow[t]{2}{*}{ Ln R\&D Employees } & & & $0.161 * * *$ & $0.159 * * *$ \\
\hline & & & $(0.028)$ & $(0.028)$ \\
\hline \multirow[t]{2}{*}{ Constant } & $-3.916^{* * *}$ & $-4.805 * * *$ & $-4.381 * * *$ & $-4.335 * * *$ \\
\hline & $(0.088)$ & $(0.099)$ & $(0.126)$ & $(0.126)$ \\
\hline Number of observations & 39,152 & 39,152 & 39,152 & 39,152 \\
\hline Pseudo $\mathrm{R}^{2}$ & 0.097 & 0.118 & 0.122 & 0.123 \\
\hline
\end{tabular}

Size, sector, capital expenditure controls and time dummies included

Robust standard errors in parentheses

$* * * \mathrm{p}<0.01, * * \mathrm{p}<0.05, * \mathrm{p}<0.1$ 
As in the case of extra-muros $R \& D$, we checked for differences in the case of collaborative linkages with Italian universities ${ }^{7}$. Table 6 illustrates results when using a dummy for technical cooperation with universities as dependent variable. There are some important similarities and diversities in this case. What is similar to the scenario we have drawn earlier, is that premia associated to group belonging are smaller for cooperation with universities than in the case of cooperation in general. This might confirm that interacting with universities is a relatively more attractive business for independent firms (and hence SMEs) due to the higher expectations of (incoming) spillovers and lower appropriability issues raised when dealing with non for-profit institutions. Different from what we obtained in the case of extra-muros R\&D to universities, however, premia do not disappear in this case: advantages associated to group belonging do persist, and continue to explain an important portion of heterogeneity in technical cooperation with universities. A possible explanation is that cooperation is more demanding in terms of organizational and technical skills, more generally speaking it requires that greater resources and commitment are devoted than in the case of R\&D contracting out. The different availability of such organizational and technical resources within groups do seem to matter a lot in the case of technical cooperation with university as well. And this militates against technical cooperation for independent firms relative to firms belonging to a group.

A further similarity with respect to previous results is that controlling for internal $\mathrm{R} \& \mathrm{D}$ efforts does improve significantly our understanding of technical cooperation, and the most relevant factor in this respect is intra-muros R\&D. However, the latter plays a stronger role here than in the case extra-muros $R \& D$ to universities. Once again, this can be used to support the idea that technical cooperation with universities requires important research capabilities, something that independent firms most often do not have.

A final aspect that is similar to what we observed earlier is the role of Italian firms that do belong to a group but also carry out R\&D activities abroad (IGFR), that are outperforming all other firm categories in this case too. What is different from previous results is that the premium for FOR firms is lower than in the case of firms belonging to Italian groups, even those that do not have any R\&D activities abroad (IGNFR), as shown in table 6 column 4 . It thus appears that being part of a group in general is an asset for technical cooperation with universities, and this is particularly the case for Italian firms that do not only belong to a group but also carry out R\&D activities abroad (IGFR); but this is much less the case of firms belonging to foreign owned (multinational) groups. The available

\footnotetext{
7 Also for the cooperation variable, the choice "cooperation with foreign universities" does exist but it is almost always equal to 0 .
}

data do not allow to go much further to explain the latter result. Suffice here to submit a few, not necessarily alternative interpretive elements that would need be checked for. On the one hand, the relatively low premium associated to FOR might have to do with the fact that, as already noted, the profile of foreign R\&D performers is relatively low and has been worsening over the past decade. On the other hand, one might suggest that foreign companies that would be capable to, and willing to, gain access to academic research, might have to deal with country specific institutional barriers. To the extent that these barriers are higher than the ones they would encounter when interacting with other research institutions at home or in other countries where multinationals are located, FOR firms might be discouraged to cooperate with Italian universities. In either case, this result is revealing of a difficulty of the Italian innovation system in using this channel to gain access to international technology flows.

To complete the analysis, we have also addressed the possible biases that might be determined by one of the measures we used to capture internal R\&D efforts, namely the ones based on R\&D employees. As anticipated in section 2, there might be non trivial problems with these measures particularly in the case of SMEs, that constitute the bulk of the ING category. Small firms are most likely to resort to part time personnel, and to multi-task workers, which might well carry out different activities, including $\mathrm{R} \& \mathrm{D}$, according to the needs and circumstances. This is likely to increase the risk that the actual workforce devoted to $\mathrm{R} \& \mathrm{D}$ is not well measured, particularly in the case of SMEs. The adoption of FTE data - which we use in all our regressions - does correct for this inconvenience, as part-time employees are more accurately accounted for, but does not fully solve the problem of multi-task workers. In fact, labor force statistics end up accounting for FTE workers in terms of their main function rather than in terms of their contributions to different activities they perform within the firm. To test for possible biases that might affect our estimates we conducted two different sets of robustness checks. First, we ran regressions substituting specifications reported in columns 3 and 4 of all tables discussed above controlling for two measures of R\&D efforts instead of three, that is intra-muros $R \& D$ expenditure and $R \& D$ persistence, thus excluding R\&D FTE employees. Second, we estimated the same equations on a subsample of firms not including firms with 10 employees or less, that is the firm category most likely to resort to part-time workers and, even more importantly, to multitask employees. Both sets of robustness checks yield results that do not substantially differ from the ones illustrated above, in terms of both significance and signs of estimated coefficients. Premia estimated for IGP and FOR, and for IGFR in particular, relative to the baseline category of ING firms, remain substantial wherever the hierarchy turned out clear in the models we have already illustrated, although the size of coefficients turns out lower in the case of the second set of robustness checks. This is not surprising as the latter 
set of regressions is based on a sub-sample that excludes micro-firms, which normally lack absorptive capacity and hence can be expected to have the lowest propensity to set up external linkages. In fact they combine the disadvantages of small size with the lower ability to join (national and international) groups. Thus, our tests seem to suggest that results shown in tables 3 through 6 are rather robust, although one cannot exclude that they are biased upward, reflecting the fact that micro-firms might indeed be particularly characterized by the employment of multi-task workers, and this could in fact determine that their actual R\&D efforts are underestimated ${ }^{8}$.

\section{Conclusion}

We have shown that the links between internal and external R\&D efforts are mediated by some structural characteristics of firms that help explain an important portion of knowledge sourcing strategies. With reference to the Italian case, we have particularly focused on group belonging as a factor that might augment firms' ability to explore, evaluate, assimilate and utilize external knowledge. From this perspective, firms that are part of multinational groups appear to be more prone to gain access to external knowledge than those belonging to uni-national groups, let alone independent firms which exhibit the lowest propensity to technology sourcing. The relative dis-advantage of independent firms, which represent the bulk of the Italian industry and include most small and medium sized enterprises, appears to be less of an obstacle in the case of linkages with universities, especially when $\mathrm{R} \& \mathrm{D}$ contracting out is considered. The increasing involvement of independent firms in this strategy of external knowledge access is playing an important role in the catching up process that these firms are undertaking to maintain and increase their competitiveness. It remains that this category of firms continues to appear in a rather weak position in the development of other technology sourcing strategies that would complement their scarce internal competencies.

The other side of the coin is represented by the diminishing involvement of foreign owned firms in R\&D activities in Italy. This is bad news for Italy, as affiliates of multinationals normally exhibit a high R\&D intensity and are able to exploit the advantages and opportunities associated to extensive internal networks of affiliates and external linkages across national borders, thus increasing their ability and propensity to exchange knowledge with external parties. In this scenario, the most dynamic part of the Italian innovation system is constituted by a very limited number of nationally owned firms that not only belong to a group but are also able to set up R\&D activities abroad. These appear to clearly outperform all other firm categories also in terms of extra-muros R\&D

\footnotetext{
8 Results of these robustness check regressions are available from the authors upon request.
}

and technological cooperation with third parties, including universities. However it is only the top of the iceberg, representative of a rather restricted oligopolistic core of the Italian industry. The overall ability of the Italian economy to access international channels of technology generation, absorption and diffusion thus remains rather weak, and this might have negative consequences on the long run perspectives of economic growth for this country.

\section{References}

Amir, Rabah, Evstigneev, Igor, John, Wooders, 2003. Noncooperative versus cooperative R\&D with endogenous spillover rates. Games and Economic Behavior 42, 184-207.

Audretsch, D. B., \& Vivarelli, M. (1996). Firms size and R\&D spillovers: Evidence from Italy. Small Business Economics, 8(3), 249-258.

Barca, F., \& Trento, S. (1997). State ownership and the evolution of Italian corporate governance. Industrial and corporate change, 6(3), 533-559.

Belderbos, R., Carree, M., Diederen, B., Lokshin, B., \& Veugelers, R. (2004). Heterogeneity in R\&D cooperation strategies. International Journal of Industrial Organization, 22(8), 1237-1263.

Belderbos, R., Carree, M., Lokshin, B., \& Sastre, J. F. (2014). Inter-temporal patterns of R\&D collaboration and innovative performance. The Journal of Technology Transfer, 1-15.

Cantwell, J. (1989). Technological innovation and multinational corporations. Oxford: Blackwell.

Cassiman, B., \& Veugelers, R. (2002). R\&D cooperation and spillovers: some empirical evidence from Belgium. American Economic Review, 11691184 .

Cassiman, B., \& Veugelers, R. (2006). In search of complementarity in innovation strategy: internal R\&D and external knowledge acquisition. Management science, 52(1), 68-82.

Cassiman, Bruno, Perez-Castrillo, David, Veugelers, Reinhilde, 2002. Endogeneizing know-how flows throughthe nature of R\&D investments. International Journal of Industrial Organisation 20, 775-799.

Castellani, D. and A. Zanfei (2006). Multinationals, Innovation and Productivity. Edward Elgar, Cheltenham.

Caves, R. E. (1996). Multinational enterprise and economic analysis. Cambridge university press.

Chun, H., \& Mun, S. B. (2012). Determinants of R\&D cooperation in small and medium-sized enterprises. Small Business Economics, 39(2), 419-436.

Cohen, W. M., \& Levinthal, D. A. (1989). Innovation and learning: the two faces of $\mathrm{R} \& \mathrm{D}$. The economic journal, 569-596. 
Cohen, W. M., \& Levinthal, D. A. (1990). Absorptive capacity: a new perspective on learning and innovation. Administrative science quarterly, 128-152.

Colajanni, N. (1991). Il capitalismo senza capitale, Milan: Sperling \& Kupfer.

Colli, A., \& Vasta, M. (eds.) (2010). Forms of Enterprises in 20th Century Italy. Boundaries, Structures and Strategies, Cheltenham-Northampton: Elgar.

Cozza, C., \& Zanfei, A. (2014). The cross border R\&D activity of italian business firms. Economia e Politica Industriale.

Dachs, B., Stehrer R. and Zahradnik G. (eds.) (2014). The Internationalisation of Business R\&D. Edward Elgar, Cheltenham.

De Bondt, R., \& Veugelers, R. (1991). Strategic investment with spillovers. European Journal of Political Economy, 7(3), 345-366.

Doms M., Jensen B. (1998) “Comparing wages, skills, and productivity between domestically and foreignowned manufacturing establishments in the United States", in Baldwin R., Lipsey R. and Richardson J.D. (eds) Geography and Ownership as Basis for Economic Accounting, University of Chicago Press.Eaton, B. C., \& Eswaran, M. (1997). Technology-trading coalitions in supergames. The Rand Journal of Economics, 135149.

Dunning, J. H. (1981). Explaining the international direct investment position of countries: towards a dynamic or developmental approach.

Weltwirtschaftliches Archiv, 117(1), 30-64.

Griffith R., Harrison R. and Van Reenen J.. (2006) "How Special is the Special Relationship? Using the impact of US R\&D spillovers on UK firms as a test of technology sourcing."American Economic Review 96, no. 5(2006) : 1859-1875

Guadalupe, M., Kuzmina, O., \& Thomas, C. (2012). Innovation and Foreign Ownership. American Economic Review, 102(7), 3594-3627.

Ietto-Gillies, G. (2001). Transnational Corporations: Fragmentation Amidst Integration (London: Routledge).

Kesteloot, K., \& Veugelers, R. (1995). Stable R\&D cooperation with spillovers. Journal of Economics \& Management Strategy, 4(4), 651-672.
Martin, S., 2002. Spillovers, appropriability, and R\&D. Journal of Economics 75 (1), 1- 32.

Narula R., \& Zanfei, A. (2005). Globalisation of Innovation. In Fagerberg, J., Mowery, D., \& Nelson, R.R. (Eds.) Handbook of Innovation, Oxford University Press, 2005: 318-345.

OECD (2002). Frascati Manual. Proposed standard practice for surveys on research and experimental development. Paris.

Piga, C. A., \& Vivarelli, M. (2004). Internal and External R\&D: A Sample Selection Approach. Oxford Bulletin of Economics and Statistics, 66(4), 457-482.

Rabbiosi, L., \& Santangelo, G. D. (2013). Parent company benefits from reverse knowledge transfer: The role of the liability of newness in MNEs. Journal of World Business, 48(1), 160-170.

Rosenberg, D. C. M. N., \& Mowery, D. C. (1989). New developments in US technology policy: implications for competitiveness and international trade policy. California Management Review.

Schmidt, T. (2010). Absorptive capacity_one size fits all? A firm-level analysis of absorptive capacity for different kinds of knowledge. Managerial and Decision Economics, 31(1), 1-18.

Segarra-Blasco, A., \& Arauzo-Carod, J. M. (2008). Sources of innovation and industry-university interaction: Evidence from Spanish firms. Research Policy, 37(8), 1283-1295.

Spithoven, A., \& Teirlinck, P. (2014). Internal capabilities, network resources and appropriation mechanisms as determinants of R\&D outsourcing. Research Policy.

Veugelers, R. (1997). Internal R \& D expenditures and external technology sourcing. Research policy, 26(3), 303-315.

Veugelers, R., \& Cassiman, B. (2005). R\&D cooperation between firms and universities. Some empirical evidence from Belgian manufacturing. International Journal of Industrial Organization, 23(5), 355-379.

Zanfei, A. (2000). Transnational Firms and the Changing Organisation of Innovative Activities, Cambridge Journal of Economics 24(5), pp. 515-542.

Zeli, A. (2002). Relazioni tra stima dell'efficienza e appartenenza a gruppi di imprese nel settore manifatturiero. Un'indagine esplorativa. Studi e note di Economia 1 (155-175). 